\title{
Pediatric Complicated Pneumonia Caused by Streptococcus pneumoniae Serotype 3 in 13-Valent Pneumococcal Conjugate Vaccinees, Portugal, 2010-2015
}

\author{
Catarina Silva-Costa, Maria João Brito, Marcos D. Pinho, Ana Friães, \\ Sandra I. Aguiar, ${ }^{1}$ M. Ramirez, Jose Melo-Cristino, on behalf of the Portuguese \\ Group for the Study of Streptococcal Infections ${ }^{2}$ and the Portuguese Study Group of \\ Invasive Pneumococcal Disease of the Pediatric Infectious Disease Society ${ }^{2}$
}

\begin{abstract}
Despite use of 7-valent pneumococcal conjugate vaccine, incidence of pleural effusion and empyema (pediatric complicated pneumococcal pneumonia [PCPP]) is reportedly increasing globally. We cultured and performed PCR on 152 pleural fluid samples recovered from pediatric patients in Portugal during 2010-2015 to identify and serotype Streptococcus pneumoniae. We identified only 17 cases by culture, but molecular methods identified $S$. pneumoniae in $68 \%(92 / 135)$ of culture-negative samples. The most frequent serotypes were 3,1 , and $19 \mathrm{~A}$, together accounting for $62 \%(68 / 109)$ of cases. Nineteen cases attributable to 13-valent pneumococcal conjugate vaccine (PCV13) serotypes (mostly serotype 3 ) were detected among 22 children age-appropriately vaccinated with PCV13. The dominance of the additional serotypes included in PCV13 among PCPP cases in Portugal continues, even with PCV13 available on the private market (without reimbursement) since 2010 and with average annual coverage of $61 \%$ among age-eligible children. Our data suggest reduced effectiveness of PCV13 against serotype 3 PCPP.
\end{abstract}

Streptococcus pneumoniae (pneumococcus) is the lead$\mathcal{N}$ ing cause of bacterial pneumonia in children and is the most common pathogen isolated in pleural effusions and empyemas (1-3). In this article, we will refer to pediatric pneumococcal pneumonias occurring with either parapneumonic effusion or empyema as pediatric complicated pneumococcal pneumonias (PCPPs). Several studies reported an increasing incidence of PCPP in the 1990s and early

Author affiliations: Instituto de Microbiologia, Instituto de Medicina Molecular, Faculdade de Medicina, Universidade de Lisboa, Lisbon, Portugal (C. Silva-Costa, M.D. Pinho, A. Friães, S.I. Aguiar, M. Ramirez, J. Melo-Cristino); Centro Hospitalar de Lisboa Central, Lisbon (M.J. Brito)

DOI: https://doi.org/10.3201/eid2407.180029 2000s $(1,2,4)$, a trend that was observed to persist or even accelerate after the introduction of the 7-valent pneumococcal conjugate vaccine (PCV7), which covered serotypes 4, 6B, 9V, 14, 18C, 19F, and 23F (1,2,4,5). Several factors could be responsible for an apparent increase in PCPP, including greater awareness and improved diagnostics (1). However, temporal trends or vaccine-induced changes in serotype prevalence and the particular propensity of certain serotypes to cause PCPP have also been implicated (1). Serotypes 1, 3, 7F, 14, and 19A are the dominant serotypes in PCPP (1), and some studies associated the increase in PCPP after the introduction of PCV7 with increasing incidence of PCPP by serotypes 1, 3, and 19A, which are not targeted by PCV7 $(1,2,6)$.

Culture of pleural fluid or blood of PCPP case-patients is frequently negative; the yield of cultures is as low as $8 \%$ for pleural fluid and only slightly higher for blood $(7,8)$. Although one of the reasons behind this low yield might be previous antimicrobial drug treatment $(9,10)$, a recent study showed that serotype 3 is infrequently cultured from children's samples but is readily detected by PCR-based assays, even without prior exposure to antibiotics (10). Although PCR-based assays for the direct detection of pneumococci from clinical samples have limitations (11), they also offer several advantages, such as speed, high sensitivity, and being independent of bacterial viability $(9,10)$. Given these advantages, PCR-based techniques are increasingly being used as important tools in the diagnosis of pneumococcal invasive infections and the epidemiologic surveillance of the characteristics of unculturable pneumococci (10).

${ }^{1}$ Current affiliation: Centro de Investigação Interdisciplinar em Sanidade Animal (CIISA), Faculdade de Medicina Veterinária, Universidade de Lisboa, Lisbon, Portugal.

${ }^{2}$ Members of the group are listed at the end of this article. 
PCV7 was introduced in Portugal in 2001. PCV10, which added serotypes 1,5 , and $7 F$ to the PCV7 serotypes, became available in mid-2009. PCV13, which added serotypes 3,6A, and 19A to the PCV10 serotypes, became available in early 2010. All PCVs were offered on the private market without any reimbursement. Even without reimbursement, $75 \%$ of children born in 2008 were vaccinated with PCV7, although soon afterward a decline in vaccination coverage occurred; coverage reached $63 \%$ in 2012 (12) and remained stable at 61\% until 2014 (unpublished data from IQVIA, Pfizer, and Instituto Nacional de Estatística, assuming a 4-dose schedule). In July 2015, PCV13 was introduced in the national immunization plan (NIP) for children born after January 2015. We conducted a prospective study to determine the serotypes causing PCPP in children in Portugal during 2010-2015, a period when PCV13 was being administered outside of the NIP.

\section{Materials and Methods}

\section{Patient Samples}

We asked 61 hospital laboratories and pediatric departments located throughout Portugal to report all cases of possible PCPP (in patients $<18$ years of age) for which pleural fluid was available for analysis and to submit these samples for characterization. We included in our study only samples recovered during January 2010-December 2015 , but we performed no audit that would ensure reporting compliance. Because our network includes all secondary and tertiary care hospitals in which PCPP is likely to be treated and a pleural fluid sample obtained, we assume our catchment population is the entire population of Portugal $<18$ years of age. During 2010-2015, this population steadily decreased, from $1,929,331$ in 2010 to $1,802,196$ in 2015 (average 1,865,288) (https://www.ine.pt).

Whenever possible, the vaccination status of the patient was also reported. We used guidelines from the Vaccines Committee of the Pediatric Infectious Diseases Society and Portuguese Pediatric Society from 2014 (13) and 2009 (14) to define age-appropriately vaccinated children with PCV7 and PCV13 (Table 1). The study was approved by the Institutional Review Board of the Centro Académico de Medicina de Lisboa.

\section{Culture-Positive Samples}

We identified all bacteria as $S$. pneumoniae by colony morphology, hemolysis on blood agar plates, optochin susceptibility, and bile solubility. We performed serotyping with the standard capsular reaction test by using the chessboard system and specific serum samples (Statens Serum Institute, Copenhagen, Denmark). For this study, we classified serotypes as vaccine serotypes (i.e., those in PCV7; the additional 3 serotypes included in PCV10 [addPCV10]; the additional 3 serotypes included in PCV13 [addPCV13]) and nonvaccine serotypes.

\section{Culture-Negative Samples}

When identification of disease etiology by conventional microbiologic methods failed, we sent pleural fluid to the central laboratory, where total DNA was extracted from $200 \mu \mathrm{L}$ of the patient sample by using the High Pure PCR Template Preparation Kit (Roche, Mannheim, Germany) or DNeasy Blood and Tissue Kit (QIAGEN, Hilden, Germany) according to the manufacturers' instructions. We used a conventional PCR amplification of 2 human genes (encoding human $\beta$-actin and RNaseP) as control for the quality of the purified DNA. We initially tested the presence of $S$. pneumoniae by using conventional PCR to target the lyt $A$ and wzg genes (2010-2011) and later (2012 and later) by using real-time PCR (rPCR). We serotyped positive samples by conventional PCR, rPCR, or a combination of both. We confirmed negative results by conventional PCR by using rPCR on samples stored at $-80^{\circ} \mathrm{C}$.

\section{Conventional PCR}

We used a multiplex PCR for the amplification of the genes encoding human $\beta$-actin and RNaseP $(15,16)$ and $S$. pneumoniae genes (lytA and wzg) $(17,18)$. We serotyped PCR-positive samples by using multiplex PCR, with primers targeting serotypes $1,3,4,5,6 \mathrm{~A}, 6 \mathrm{~B}, 6 \mathrm{C}, 7 \mathrm{~F}$,

Table 1. PCV immunization schemes according to guidelines from the Vaccines Committee of the Pediatric Infectious Diseases Society and Portuguese Pediatric Society*

\begin{tabular}{|c|c|c|c|}
\hline Vaccine & Start of vaccination scheme & Primary immunization course & Booster vaccination \\
\hline PCV7 & $\begin{array}{c}2-6 \mathrm{mo} \\
7-11 \mathrm{mo} \\
12-23 \mathrm{mo} \\
24-59 \mathrm{mo}\end{array}$ & $\begin{array}{c}3 \text { doses, at } 2,4, \text { and } 6 \mathrm{mo} \\
2 \text { doses } \\
2 \text { doses } \ddagger \\
\text { Risk group only: } 2 \text { doses }\end{array}$ & $\begin{array}{c}12-15 \text { mo } \\
\text { Booster dose at } 12 \text { mo† } \\
\text { NA } \\
\text { NA }\end{array}$ \\
\hline PCV13 & $\begin{array}{c}2-6 \mathrm{mo} \\
7-11 \mathrm{mo} \\
12-23 \mathrm{mo} \\
>24 \mathrm{mo}\end{array}$ & $\begin{array}{c}2 \text { or } 3 \text { doses } \S \\
2 \text { doses } \\
2 \text { doses } \ddagger \\
1 \text { dose }\end{array}$ & $\begin{array}{l}\text { 11-15 mol } \\
11-15 \text { mol } \\
\text { NA } \\
\text { NA }\end{array}$ \\
\hline
\end{tabular}

${ }^{*} \mathrm{NA}$, not applicable; PCV, pneumococcal conjugate vaccine; PCV7, 7-valent PCV; PCV13, 13-valent PCV. 
$8,9 \mathrm{~V}, 14,15 \mathrm{~A}, 15 \mathrm{~B} / \mathrm{C}, 16,18 \mathrm{C}, 19 \mathrm{~A}$, and $23 \mathrm{~F}(17,19)$. We performed PCR reactions in a final volume of $25 \mu \mathrm{L}$ containing $4 \mu \mathrm{L}$ of DNA, 1X polymerase buffer (Biotools, Madrid, Spain), 3U of polymerase GoTaq (Biotools, Madrid, Spain), $10 \mathrm{mmol} / \mathrm{L}$ dNTPs, and $10 \mathrm{pmol}$ of each primer (with the exception of human $\beta$-actin primers, for which 7 pmol was used). The PCR program consisted of 4 min denaturation at $95^{\circ} \mathrm{C}, 30$ cycles of $95^{\circ} \mathrm{C}$ for $40 \mathrm{~s}$, $58^{\circ} \mathrm{C}$ for $40 \mathrm{~s}$, and $65^{\circ} \mathrm{C}$ for $2 \mathrm{~min}$, followed by a final extension at $65^{\circ} \mathrm{C}$ for $10 \mathrm{~min}$.

\section{rPCR}

We performed rPCR on the Rotor-Gene 6000 (Corbett Research, Cambridge, United Kingdom) by using the Platinum quantitative PCR SuperMix-UDG (Thermo Fisher Scientific, Waltham, Massachusetts, USA). PCR reactions contained $5 \mu \mathrm{L}$ of DNA, $5 \mathrm{pmol} / \mathrm{L}$ of each primer (targeting lyt $A$ and $w z g$ genes) $(18,20), 2.5 \mathrm{pmol} / \mathrm{L}$ of each probe, 12.5 $\mu \mathrm{L}$ of PCR SuperMix-UDG, $1.5 \mu \mathrm{L}$ of $\mathrm{MgCl}_{2}(50 \mathrm{nmol} / \mathrm{L})$, and water, for a final volume of $25 \mu \mathrm{L}$. Cycling conditions were as follows: $95^{\circ} \mathrm{C}$ for $10 \mathrm{~min}$, followed by 50 cycles at $95^{\circ} \mathrm{C}$ for $15 \mathrm{~s}$ and $60^{\circ} \mathrm{C}$ for $1 \mathrm{~min}$. We performed detection of $l y t A$ and $w z g$ in singleplex PCR. We defined negative results as those with cycle threshold $\left(\mathrm{C}_{\mathrm{t}}\right)>40$ and positive results as those with $\mathrm{C}_{t} \leq 35(21)$. If a $\mathrm{C}_{t}$ value $>35$ and $\leq 40$ was obtained, we considered the result inconclusive and varied the amount of DNA in the reaction by using twice as much DNA and diluting over a 50-fold range. If still no reaction yielded a $\mathrm{C}_{\mathrm{t}} \leq 35$, we considered the sample negative.

For serotyping by rPCR (22), we performed 7 multiplex reactions targeting 3 serotypes or serogroups each: 3 , $7 \mathrm{~F} / 7 \mathrm{~A}$, and $19 \mathrm{~A} ; 1,15 \mathrm{~B} / 15 \mathrm{C}$, and $23 \mathrm{~F} ; 14,18 \mathrm{C}$, and $19 \mathrm{~F}$; 4,6 , and $9 \mathrm{~V} / 9 \mathrm{~A} ; 5,11 \mathrm{~A} / 11 \mathrm{D}$, and $16 \mathrm{~F} ; 8,12 \mathrm{~F} / 12 \mathrm{~A} / 12 \mathrm{~B}$, and $22 \mathrm{~F} / 22 \mathrm{~A}$; and $15 \mathrm{~A}, 23 \mathrm{~A}$, and $33 \mathrm{~F} / 33 \mathrm{~A} / 37$. We also used rPCR to serotype positive samples that tested negative for all serotypes by conventional PCR. The rPCR scheme for serotyping did not enable discrimination between some serotypes within a few serogroups, as indicated in the description of each multiplex reaction.

\section{Statistical Methods}

We used the Fisher exact test to evaluate differences in the prevalence of the most frequent addPCV10 and addPCV13 serotypes, as well as the number of PCPPs among vaccinated and nonvaccinated children. We consider a $p$ value
$<0.05$ statistically significant. We report patient age as median years and interquartile range (IQR).

\section{Results}

\section{Patient Samples}

During January 2010-December 2015, we analyzed 152 pleural fluid samples; 17 cases were identified by culture to have pneumococcal etiology by the participating laboratories. We submitted 135 culture-negative samples to the central laboratory for molecular testing. In 43 samples, we did not detect $S$. pneumoniae in the pleural fluid by molecular methods, but we confirmed the remaining 92 cases $(68 \%)$ to be PCPP by molecular methods. The total numbers of requests for molecular testing and samples positive for $S$. pneumoniae were approximately constant over the years (Table 2).

\section{PCPP Case-Patients}

Among the 109 PCPP case-patients (17 identified by culture and 92 by molecular methods), 56 were male and 52 female; the sex of 1 patient was not available. Patient age ranged from 4 months to 17 years (median age 4 [IQR 2.3-6] years); 27 cases were in children $\leq 2$ years of age. A total of 34 (31\%) PCPP cases occurred in nonvaccinated children (median age 2.6 [IQR 1.4-8.5] years), and the vaccination status was unknown for $28(26 \%)$ patients. The remaining 47 (43\%) PCPP cases occurred in children who received $\geq 1$ vaccine dose (median age 3.2 [IQR 3-5] years). All vaccinated children received PCV7, PCV13, or both; PCV10 had not been administered to any child in the study.

\section{Serotypes of PCPP Case-Patients}

Except for $18(16 \%)$ samples, we were able identify the serotypes of the pneumococci responsible for illness (Table 3). Overall, the most frequent serotype was serotype 3 , responsible for $36 \%$ of the PCPP cases $(n=40$; median patient age 3 [IQR 2-5] years), followed by serotype 1 (n $=21$ [19\% of cases]; median patient age 5.5 [IQR 4-13.5] years). Other serotypes found were $19 \mathrm{~A}(\mathrm{n}=7) ; 7 \mathrm{~F} / 7 \mathrm{~A}(\mathrm{n}=$ 4); $14(\mathrm{n}=3) ; 5,16 \mathrm{~F}$, and $7 \mathrm{~F}(\mathrm{n}=2$ each); and $6 \mathrm{~B}, 6,8,9 \mathrm{~V}$, 9V/A, 10A, 15A, 19F, 23F, and 33F/33A/37 ( $=1$ each); median patient age for all of these cases was 3 (IQR 1-6) years. Although serotype 1 cases occurred more frequently among older children than serotype 3 cases $(p=0.005$ by

Table 2. Number of requests for laboratory testing and confirmed positive cases of Streptococcus pneumoniae infection in children, Portugal, 2010-2015*

\begin{tabular}{lcccccc}
\hline & \multicolumn{3}{c}{ Year } \\
\cline { 2 - 7 } Cases and requests & 2010 & 2011 & 2012 & 2013 & 2014 & 2015 \\
\hline Positive for S. pneumoniae & 29 & 18 & 19 & 18 & 10 & 15 \\
Negative for S. pneumoniae & 2 & 3 & 8 & 10 & 6 & 14 \\
Requests & 31 & 21 & 27 & 28 & 16 & 29 \\
\hline
\end{tabular}

${ }^{*}$ Among the cases are 17 for which pneumococci were cultured from pleural fluid $(2010, n=5 ; 2011, n=3 ; 2012, n=2 ; 2013, n=3 ; 2014, n=0 ;$ and 2015, $n=4)$. 
Table 3. Serotype distribution among the 152 pediatric case-patients with Streptococcus pneumoniae infection included in this study, by PCV vaccination status, Portugal, 2010-2015*

\begin{tabular}{|c|c|c|c|c|c|c|c|}
\hline \multirow[b]{2}{*}{ Serotype } & \multicolumn{7}{|c|}{ Vaccination status } \\
\hline & AP_PCV13 & AP_PCV7 & NA_PCV13 & NA_PCV7 & Not vaccinated & Unknown & Total \\
\hline 14 & 1 & & & & 2 & & 3 \\
\hline $19 \mathrm{~F}$ & & & & & & 1 & 1 \\
\hline $23 \mathrm{~F}$ & & & & & & 1 & 1 \\
\hline PCV7 & 1 & & 1 & & 2 & 2 & 6 \\
\hline 1 & 1 & 3 & & 2 & 7 & 8 & 21 \\
\hline 5 & & 1 & & & & 1 & 2 \\
\hline PCV10 & 2 & 4 & 1 & 4 & 9 & 11 & 31 \\
\hline 3 & 17 & 6 & & 1 & 11 & 5 & 40 \\
\hline $19 \mathrm{~A}$ & & 1 & & & 5 & 1 & 7 \\
\hline PCV13 & 19 & 11 & 1 & 5 & 26 & 17 & 79 \\
\hline $16 \mathrm{~F}$ & & & & & & 2 & 2 \\
\hline 8 & & & & 1 & & & 1 \\
\hline $15 \mathrm{~A}$ & & & & & 1 & & 1 \\
\hline $10 \mathrm{~A}$ & & & 1 & & & & 1 \\
\hline 7F/7A & & 1 & & $3 \dagger$ & & 2 & 6 \\
\hline 6 & & & & & $2 \ddagger$ & & 2 \\
\hline 9V/9A & & & $1 \S$ & & 1 & & 2 \\
\hline $33 F / 33 A / 37$ & & & 1 & & & & 1 \\
\hline Nonvaccine type & & 1 & 2 & 2 & 3 & 4 & 12 \\
\hline Not identified & 3 & 1 & 1 & 1 & 5 & 7 & 18 \\
\hline Total & 22 & 13 & 4 & 8 & 34 & 28 & 109 \\
\hline $\begin{array}{l}\text { *AP_PCV13, age-app } \\
\text { vaccinated with PCV } \\
\text { 13-valent PCV. } \\
\text { †Serotype 7F }(n=2) \\
\text { †Serotype 6B }(n=1) \\
\text { §Serotype 9V }(n=1)\end{array}$ & $\begin{array}{l}\text { priately vaccin } \\
\text { NA_PCV7, no }\end{array}$ & $\begin{array}{l}\text { with PCV13; } \\
\text {-appropriate }\end{array}$ & $\begin{array}{l}\mathrm{CV} 7 \text {, age-app } \\
\text { cinated with } \mathrm{P}\end{array}$ & $\begin{array}{l}\text { ately vaccina } \\
\text { PCV, pneum }\end{array}$ & $\begin{array}{l}\text { with PCV7; NA_PC } \\
\text { ccal conjugate vac }\end{array}$ & $\begin{array}{l}\text {, not age-ap } \\
\text { PCV7, 7-v }\end{array}$ & $\begin{array}{l}\text { ely } \\
\text { V; PCV }\end{array}$ \\
\hline
\end{tabular}

Fisher exact test), the age distribution of the case-patients infected with each of these serotypes was not significantly different from that of PCPP case-patients infected with all other serotypes ( $\mathrm{p} \geq 0.198$ by Fisher exact test). Whenever possible, conventional PCR serotyping enabled the identification of serotypes $7 \mathrm{~F}, 6 \mathrm{~B}$, and $9 \mathrm{~V}$, whereas rPCR detected only the groups $9 \mathrm{~V} / 9 \mathrm{~A}, 7 \mathrm{~F} / 7 \mathrm{~A}$, and 6 without further discrimination. On the 17 culture-positive samples, only 5 serotypes were found: 1 and $3(\mathrm{n}=7$ each) and 14, 10A, and 19A $(\mathrm{n}=1 \mathrm{each})$. Apart from serotype 10A, which was detected exclusively in 1 isolate, all other serotypes were also detected by PCR from culture-negative samples. Most of the PCPP case-patients for whom a serotype was unambiguously identified were infected with the addPCV13 serotypes $(n=47[43 \%])$, followed by the addPCV10 serotypes ( $\mathrm{n}=25[23 \%])$, whereas PCV7 serotypes were responsible for a small fraction of PCPP cases $(n=7[6 \%])$. Among the remaining cases, 6 were caused by nonvaccine serotypes, and in another 6 cases, we were unable to classify capsular types as vaccine or nonvaccine type. These cases included samples for which rPCR tested positive for serogroup $6(n=1), 7 F / 7 A(n=4)$, or 9V/9A $(n=1)$.

\section{Vaccination Status of PCPP Case-Patients}

Among the 47 vaccinated children, 35 were age-appropriately vaccinated (Table 3 ). Of these 35 children (median age 4 [IQR 5.5-6] years), 13 had received 4 doses of PCV13 and 13 (median age 5 [IQR 3-5] years) had received 4 doses of PCV7; the remaining children had received fewer doses $(n=6)$ or a combination of both PCVs $(\mathrm{n}=3)$. Among the 22 children age-appropriately vaccinated with PCV13, 19 had infections caused by serotypes included in PCV13, representing vaccine failures. These cases occurred throughout the study period ( 1 case in 2010 , 2 in 2012, 9 in 2013, and 7 in 2015). Among this group were 12 children (median age 3 [IQR 3-3.5] years) who had completed a 4-dose scheme of PCV13; 11 had serotype 3 PCPP and 1 serotype 1 PCPP. We also identified serotype 3 in 4 of 6 PCPPs in children who were age-appropriately vaccinated and had received 3 doses of PVC13 (1 case in a 1.5-year-old child, 2 in 2-year-old children, and 1 in a 3 -year-old child). Among children who received a combination of both conjugate vaccines, a series of 3 or 4 doses of PCV7 followed by 1 dose of PCV13 serotype 3 was detected in 2 case-patients (both 6-year-olds) and serotype 14 in 1 case-patient (a 3.5-year-old). Among the 13 children age-appropriately vaccinated with PCV7 (median age 5 [IQR 3-5] years), all had received 4 PCV7 doses, and we detected no cases caused by PCV7 serotypes. Most cases were caused by addPCV13 serotypes; serotype 3 was most prevalent $(n=6)$, followed by serotype $1(n=3)$, and serotypes 5 and 19A $(\mathrm{n}=1$ each).

We compared the number of addPCV10 and addPCV13 PCPP cases (i.e., those caused by serotypes 1 , 3, 19A, and 7F) among children age-appropriately vaccinated with PCV13 and among the other case-patients for 
whom vaccination status was known and serotype could be unambiguously determined. Serotype 3 was overrepresented among PCPP cases in children age-appropriately vaccinated with PCV13 ( $<<0.001$ by Fisher exact test). We detected a similar number of positive samples for $S$. pneumoniae among children age-appropriately vaccinated with PCV13 ( $n=22 / 27)$ and among the other case-patients for whom vaccination status was known $(n=59 / 71)(\mathrm{p}=1$ by Fisher exact test).

\section{Discussion}

The detection of $S$. pneumoniae in pleural fluid samples was greatly improved by the use of molecular methods, as previously reported (3); only 17 culture-positive cases of 109 were confirmed PCPPs (16\%). Serotype 3 and the other major serotypes found (1, 19A, 7F/7A, and 14) have already been associated with complicated pneumonias and pneumococcal empyemas worldwide (3,9,23-26). Serotypes 1,19A, and 14 were important causes of pediatric invasive pneumococcal disease (IPD) in Portugal during 2008-2012 (12) and were also among the most prevalent in PCPPs; however, serotype 3, which accounted for a small fraction of pediatric IPD cases during 2008-2012 ( $\mathrm{n}=9$ [2\%]) was the most frequent serotype in PCPPs. Although several factors might explain this difference, serotype 3 isolates might be more prone to specifically invade the pleural space and cause complicated pneumonia, with or without empyema. Supporting this hypothesis, a previous study found that pneumonia caused by serotype 3 was associated with an increased risk for necrotizing pneumonia, associated parapneumonic empyema, and increased severity of illness (25).

In the group of children vaccinated with PCV13, the most frequent serotype was 3 , despite the potential protection conferred by vaccination. In fact, serotype 3 cases were more prevalent among children age-appropriately vaccinated with PCV13 than among the other case-patients for which vaccination status was known. One possible explanation for this could be a more limited protection of PCV13 against serotype 3 PCPP and a more effective protection against other serotypes, namely the other most prevalent serotypes (1,7F and 19A), which would increase the likelihood that any PCPP cases in this group would be caused by serotype 3 .

The effectiveness of PCV13 against serotype 3 has been questioned in several studies. In a large surveillance study performed in the United States, no reduction in IPD caused by serotype 3 was observed despite reductions in IPD incidence and evident decreases in IPD caused by PCV13 serotypes 19A and 7F (27). A postlicensure indirect cohort study in England, Wales, and Northern Ireland to assess vaccine effectiveness against IPD indicated that, for serotype 3 , the calculated correlate of protection was $2.83 \mu \mathrm{g} / \mathrm{mL}$, which is much higher than the $0.35 \mu \mathrm{g} / \mathrm{mL}$ aggregate correlate of protection used during licensing, suggesting a potential explanation for the reduced effectiveness of PCV13 against this serotype (28). The cases of serotype 3 PCPP in our study among children age-appropriately vaccinated with PCV13 occurred mostly in children $\geq 3$ years of age $(n=12 / 17)$, but the distribution was similar to that of serotype 3 casepatients not vaccinated with PCV13 ( $\mathrm{p}=0.353$ by Fisher exact test), so it does not seem likely that this was attributable to faster waning of the immune response to this serotype. In fact, cases of serotype 3 PCPP occurred in younger children than did cases caused by serotype 1 , a serotype also included in PCV13 and for which only 1 vaccine failure was detected. Because the synthesis of the serotype 3 capsular polysaccharide proceeds through a synthase mechanism, the polysaccharide is not covalently linked to the peptidoglycan and can be released during growth, thereby potentially reducing opsonophagocytosis $(29,30)$. Free capsular polysaccharide in pleural effusions in vitro can also neutralize type-specific anticapsular antibody, further reducing the efficacy of antibody-mediated clearance (26), and the considerable amounts of capsule produced could further enhance these effects in serotype 3 strains. Taken together, these data suggest that PCV13 might offer more limited individual protection against serotype 3 , particularly in the context of complicated pneumonia.

The proportion of children asymptomatically colonized with serotype 3 increased in the period preceding PCV13 introduction in Portugal (31), but no data are available for more recent years. However, serotype 3 is currently the most important serotype among pneumococcal infections in adults $(32,33)$, suggesting substantial circulation of these strains. Even so, if PCV13 in the NIP reduces colonization by serotype 3 isolates, its overall effectiveness could be much higher than the individual protection afforded because a reduction of the circulation of serotype 3 would also mean less opportunities to cause infection. Such an effect could be behind the decrease in PCPP observed with the introduction of PCV13 in several countries $(2,5)$.

In agreement with our observations, other reports document serotype 3 vaccine failures. A study in Greece found 5 cases of complicated pneumonia caused by serotype 3 pneumococci among vaccinated children, although most vaccine failures occurred in children who received a single dose of PCV13, which could offer only limited protection (34). A more recent report, also from Greece, found 4 cases of empyema caused by serotype 3 pneumococci among children vaccinated with either a 3-plus-1 schedule $(n=3)$ or a booster dose at the age of 21 months $(n=1)(35)$, which can be considered vaccine failures. A study from Catalonia, Spain, also found 9 vaccine 
failures among 86 cases of IPD, mostly caused by serotype $3(n=6)$, including 2 cases in children who had received 4 vaccine doses (36).

Although our study was prospective and involved both pediatric and microbiology departments, it was not designed to estimate the incidence of PCPP because it did not identify cases in which there were clinical or radiographic criteria for complicated pneumonia and for which pneumococci were identified in either blood or respiratory samples. Although this certainly resulted in an underestimation of PCPP, the use of conventional PCR and rPCR techniques greatly enhanced the ascertainment of PCPP cases by improving the detection of $S$. pneumoniae in pleural fluid samples and emphasizes the potential role of molecular techniques when evaluating disease incidence. Another limitation of our study is lack of detailed information about the immune status or other underlying conditions in ageappropriately vaccinated children with PCPP by vaccine serotype. However, given the high prevalence of serotype 3 in this group, it is unlikely that all cases could be explained by host characteristics, indicating that specific properties of serotype 3 must be responsible for this behavior.

In summary, we describe data that are compatible with a lower individual effectiveness of PCV13 against PCPP, a presentation of IPD for which PCV13 is specifically recommended. The public health consequences of such possible lower protection might be mitigated by a reduction in circulating serotype 3 by vaccination with very high coverage, such as those achieved through inclusion in NIPs. Carriage studies and continued surveillance are necessary to determine the group effect of the introduction of PCV13 in the NIP to clarify the effectiveness of PCV13 in the prevention of infections caused by serotype 3 .

Members of the Portuguese Group for the Study of Streptococcal Infections: Teresa Vaz, Marília Gião, Rui Ferreira, Ana Buschy Fonseca, Henrique Oliveira, Ana Cristina Silva, Hermínia Costa, Margarida Pinto, Odete Chantre, João Marques, Isabel Peres, Isabel Daniel, Ema Canas, Teresa Ferreira, Cristina Marcelo, Lurdes Monteiro, Luís Marques Lito, Teresa Marques, Filomena Martins, Maria Ana Pessanha, Elsa Gonçalves, Teresa Morais, Paulo Lopes, Luísa Felício, Angelina Lameirão, Ana Paula Mota Vieira, Margarida Tomaz, Rosa Bento, Maria Helena Ramos, Ana Paula Castro, Fernando Fonseca, Ana P. Castro, Graça Ribeiro, Rui Tomé, Celeste Pontes, Luísa Boaventura, Nuno Canhoto, Teresa Afonso, Teresa Pina, Helena Peres, Ilse Fontes, Paulo Martinho, Ana Domingos, Gina Marrão, José Grossinho, Manuela Ribeiro, Alberta Faustino, Adelaide Alves, Maria Paula Pinheiro, R. Semedo, Adriana Coutinho, Luísa Cabral, Olga Neto, Luísa Sancho, José Diogo, Ana Rodrigues, Isabel Nascimento, Elmano Ramalheira, Fernanda Bessa, I. Marques, José Miguel Ribeiro, Maria Antónia Read, Valquíria Alves, Engrácia Raposo, Maria Lurdes Magalhães, Helena Rochas,
Anabela Silva, Margarida Rodrigues, Maria Favila Meneses, José Germano de Sousa, Mariana Bettencourt Viana, Isaura Terra, Vitória Rodrigues, Patrícia Pereira, Jesuína Duarte, Paula Pinto, Ezequiel Moreira, João Ataíde Ferreira, Adília Vicente, Paulo Paixão, Natália Novais.

Members of the Portuguese Study Group of Invasive Pneumococcal Disease of the Pediatric Infectious Disease Society: Sónia Aires, Cristina Ferreira, Eurico Gaspar, Manuela Ferreira, Fernanda Pereira, Maria José Dinis, Álvaro Sousa, Paulo Teixeira, José Amorim, Cláudia Monteiro, Isabel Carvalho, Sofia Arosa, Margarida Guedes, Laura Marques, Ana Braga, Margarida Tavares, Isabel Cunha, Lurdes Vicente, Maria Manuel Zarcos, Helena Almeida, Sílvia Almeida, Fernanda Rodrigues, Cristina Resende, Eulália Afonso, Luísa Mendes, Cristina Faria, Ana Luísa Teixeira, António Mendes, Teresa Tomé, Mónica Rebelo, Maria João Brito, Filomena Pereira, Gustavo Rodrigues, Alexandra Costa, Ana Teixeira, Sofia Lima, Érica Laima, Maria Ana S. Nunes, Filipa Prata, Pedro Flores, Manuela Brandão, João Calado Nunes, Rosário Massa, Florbela Cunha, Paula Correia, Anabela Brito, João Franco, Cristina Didelet, Estela Veiga, Carla Cruz, Graça Seves, Céu Novais, Maria João Virtuoso, Nancy Guerreiro, Amélia Cavaco, Francisco Gomes, Dora Gomes, Isabel Monteiro.

S.I. Aguiar was supported by grant SFRH/BPD/78376/2011 from Fundação para a Ciência e Tecnologia, Portugal. The work was partly supported by Fundação para a Ciência e Tecnologia, Portugal (PTDC/DTP-EPI/1759/2012 and PTDC/ DTP-EPI/1555/2014) and an unrestricted investigator-initiated project from Pfizer. The funders had no role in study design, data collection and analysis, decision to publish, or preparation of the manuscript.

\section{About the Author}

Dr. Silva-Costa holds a $\mathrm{PhD}$ in microbiology and is an assistant professor at the University of Lisbon Medical School. Her current main interests are the epidemiological study of streptococcal infections with a focus on pneumococcal pediatric invasive disease and the impact of conjugate vaccines.

\section{References}

1. Fletcher MA, Schmitt H-J, Syrochkina M, Sylvester G. Pneumococcal empyema and complicated pneumonias: global trends in incidence, prevalence, and serotype epidemiology. Eur J Clin Microbiol Infect Dis. 2014;33:879-910. http://dx.doi.org/10.1007/s10096-014-2062-6

2. Nath S, Thomas M, Spencer D, Turner S. Has the incidence of empyema in Scottish children continued to increase beyond 2005? Arch Dis Child. 2015;100:255-8. http://dx.doi.org/10.1136/ archdischild-2014-306525

3. Strachan RE, Cornelius A, Gilbert GL, Gulliver T, Martin A, McDonald T, et al.; Australian Research Network in Empyema. Bacterial causes of empyema in children, Australia, 2007-2009. Emerg Infect Dis. 2011;17:1839-45. http://dx.doi.org/10.3201/ eid1710.101825 
4. Yu D, Buchvald F, Brandt B, Nielsen KG. Seventeen-year study shows rise in parapneumonic effusion and empyema with higher treatment failure after chest tube drainage. Acta Paediatr. 2014;103:93-9. http://dx.doi.org/10.1111/apa.12426

5. Wiese AD, Griffin MR, Zhu Y, Mitchel EF Jr, Grijalva CG. Changes in empyema among U.S. children in the pneumococcal conjugate vaccine era. Vaccine. 2016;34:6243-9. http://dx.doi.org/10.1016/j.vaccine.2016.10.062

6. Thomas MF, Sheppard CL, Guiver M, Slack MPE, George RC, Gorton R, et al. Emergence of pneumococcal 19A empyema in UK children. Arch Dis Child. 2012;97:1070-2. http://dx.doi.org/10.1136/archdischild-2012-301790

7. Tarragó D, Fenoll A, Sánchez-Tatay D, Arroyo LA, Muñoz-Almagro C, Esteva C, et al. Identification of pneumococcal serotypes from culture-negative clinical specimens by novel real-time PCR. Clin Microbiol Infect. 2008;14:828-34. http://dx.doi.org/10.1111/j.1469-0691.2008.02028.x

8. Jiménez D, Díaz G, García-Rull S, Vidal R, Sueiro A, Light RW. Routine use of pleural fluid cultures. Are they indicated? Limited yield, minimal impact on treatment decisions. Respir Med. 2006;100:2048-52. http://dx.doi.org/10.1016/j.rmed.2006.02.008

9. Obando I, Muñoz-Almagro C, Arroyo LA, Tarrago D, Sanchez-Tatay D, Moreno-Perez D, et al. Pediatric parapneumonic empyema, Spain. Emerg Infect Dis. 2008;14:1390-7. http://dx.doi.org/10.3201/eid1409.071094

10. Selva L, Ciruela P, Esteva C, de Sevilla MF, Codina G, Hernandez S, et al. Serotype 3 is a common serotype causing invasive pneumococcal disease in children less than 5 years old, as identified by real-time PCR. Eur J Clin Microbiol Infect Dis. 2012;31:1487-95. http://dx.doi.org/10.1007/s10096-011-1468-7

11. Ramirez M, Melo-Cristino J. Expanding the diagnosis of pediatric bacteremic pneumococcal pneumonia from blood cultures to molecular methods: advantages and caveats. Clin Infect Dis. 2010;51:1050-2. http://dx.doi.org/10.1086/656580

12. Aguiar SI, Brito MJ, Horácio AN, Lopes JP, Ramirez M, Melo-Cristino J, et al.; Portuguese Group for the Study of Streptococcal Infections; Portuguese Study Group of Invasive Pneumococcal Disease of the Paediatric Infectious Disease Society. Decreasing incidence and changes in serotype distribution of invasive pneumococcal disease in persons aged under 18 years since introduction of 10-valent and 13-valent conjugate vaccines in Portugal, July 2008 to June 2012. Euro Surveill. 2014;19:20750. http://dx.doi.org/10.2807/1560-7917.ES2014.19.12.20750

13. Vaccines Committee of the Pediatric Infectious Diseases Society. Vaccine recommendations: 2014 update [in Portuguese] [cited 2018 Jan 8]. http://www.spp.pt/UserFiles/file/Comissao_de_Vacinas/ RECOMENDACOES SOBRE VACINAS EXTRA PNV 2014\%20 1 \% 20 FINAL.pdf

14. Vaccine Committee of the Pediatric Infectious Diseases Society and Portuguese Pediatric Society. Guidelines for pneumococcal vaccination [in Portuguese] [cited 2018 Jan 8]. http://www.spp.pt/UserFiles/file/Comissao_de_Vacinas/ Vacina_Antipneumococica_2009.pdf

15. Drake WP, Pei Z, Pride DT, Collins RD, Cover TL, Blaser MJ. Molecular analysis of sarcoidosis tissues for mycobacterium species DNA. Emerg Infect Dis. 2002;8:1334-41. http://dx.doi.org/10.3201/eid0811.020318

16. US Centers for Disease Control and Prevention. Real-time (TaqMan) RT-PCR assay for the detection of mumps virus RNA in clinical samples [cited 2016 Apr 6]. http://www.cdc.gov/mumps/ downloads/lab-rt-pcr-assay-detect.doc

17. Brito DA, Ramirez M, de Lencastre H. Serotyping Streptococcus pneumoniae by multiplex PCR. J Clin Microbiol. 2003;41: 2378-84. http://dx.doi.org/10.1128/JCM.41.6.2378-2384.2003

18. Carvalho MG, Tondella ML, McCaustland K, Weidlich L, McGee L, Mayer LW, et al. Evaluation and improvement of real-time PCR assays targeting lytA, ply, and psaA genes for detection of pneumococcal DNA. J Clin Microbiol. 2007;45:24606. http://dx.doi.org/10.1128/JCM.02498-06

19. Pai R, Gertz RE, Beall B. Sequential multiplex PCR approach for determining capsular serotypes of Streptococcus pneumoniae isolates. J Clin Microbiol. 2006;44:124-31. http://dx.doi.org/ 10.1128/JCM.44.1.124-131.2006

20. Park HK, Lee HJ, Kim W. Real-time PCR assays for the detection and quantification of Streptococcus pneumoniae. FEMS Microbiol Lett. 2010;310:48-53. http://dx.doi.org/10.1111/ j.1574-6968.2010.02044.x

21. Centers for Disease Control and Prevention. PCR for detection and characterization of bacterial meningitis pathogens: Neisseria meningitidis, Haemophilus influenzae, and Streptococcus pneumonia [chapter]. In: Laboratory methods for the diagnosis of meningitis caused by Neisseria meningitidis, Streptococcus pneumoniae, and Haemophilus influenzae, WHO manual, second edition. Atlanta: Centers for Disease Control and Prevention; 2011 [cited 2016 Apr 22]. https://www.cdc.gov/meningitis/lab-manual/ full-manual.pdf

22. Centers for Disease Control and Prevention. PCR deduction of pneumococcal serotypes [cited 2016 Apr 22]. http://www.cdc.gov/ streplab/pcr.html

23. Fletcher MA, Schmitt H-J, Syrochkina M, Sylvester G. Pneumococcal empyema and complicated pneumonias: global trends in incidence, prevalence, and serotype epidemiology. Eur J Clin Microbiol Infect Dis. 2014;33:879-910. http://dx.doi.org/ 10.1007/s10096-014-2062-6

24. Slinger R, Hyde L, Moldovan I, Chan F, Pernica JM. Direct Streptococcus pneumoniae real-time PCR serotyping from pediatric parapneumonic effusions. BMC Pediatr. 2014;14:189. http://dx.doi.org/10.1186/1471-2431-14-189

25. Bender JM, Ampofo K, Korgenski K, Daly J, Pavia AT, Mason EO, et al. Pneumococcal necrotizing pneumonia in Utah: does serotype matter? Clin Infect Dis. 2008;46:1346-52. http://dx.doi.org/10.1086/586747

26. Yu J, Salamon D, Marcon M, Nahm MH. Pneumococcal serotypes causing pneumonia with pleural effusion in pediatric patients. J Clin Microbiol. 2011;49:534-8. http://dx.doi.org/10.1128/ JCM.01827-10

27. Moore MR, Link-Gelles R, Schaffner W, Lynfield R, Lexau C, Bennett NM, et al. Effect of use of 13-valent pneumococcal conjugate vaccine in children on invasive pneumococcal disease in children and adults in the USA: analysis of multisite, populationbased surveillance. Lancet Infect Dis. 2015;15:301-9. http://dx.doi.org/10.1016/S1473-3099(14)71081-3

28. Andrews NJ, Waight PA, Burbidge P, Pearce E, Roalfe L, Zancolli M, et al. Serotype-specific effectiveness and correlates of protection for the 13-valent pneumococcal conjugate vaccine: a postlicensure indirect cohort study. Lancet Infect Dis. 2014;14:839-46. http://dx.doi.org/10.1016/ S1473-3099(14)70822-9

29. Choi EH, Zhang F, Lu Y-J, Malley R. Capsular polysaccharide (CPS) release by serotype 3 pneumococcal strains reduces the protective effect of anti-type 3 CPS antibodies. Clin Vaccine Immunol. 2015;23:162-7. http://dx.doi.org/10.1128/ CVI.00591-15

30. García E, Arrecubieta C, Muñoz R, Mollerach M, López R. A functional analysis of the Streptococcus pneumoniae genes involved in the synthesis of type 1 and type 3 capsular polysaccharides. Microb Drug Resist. 1997;3:73-88. http://dx.doi.org/10.1089/mdr.1997.3.73

31. Rodrigues F, Foster D, Caramelo F, Serranho P, Gonçalves G, Januário L, et al. Progressive changes in pneumococcal carriage in children attending daycare in Portugal after 6 years of gradual conjugate vaccine introduction show falls in most 
residual vaccine serotypes but no net replacement or trends in diversity. Vaccine. 2012;30:3951-6. http://dx.doi.org/10.1016/ j.vaccine.2012.03.058

32. Horácio AN, Silva-Costa C, Lopes JP, Ramirez M, Melo-Cristino J; Portuguese Group for the Study of Streptococcal Infections. Serotype 3 remains the leading cause of invasive pneumococcal disease in adults in Portugal (2012-2014) despite continued reductions in other 13-valent conjugate vaccine serotypes. Front Microbiol. 2016;7:1616. http://dx.doi.org/10.3389/ fmicb.2016.01616

33. Horácio AN, Lopes JP, Ramirez M, Melo-Cristino J; Portuguese Group for the Study of Streptococcal Infections. Non-invasive pneumococcal pneumonia in Portugal - serotype distribution and antimicrobial resistance. PLoS One. 2014;9:e103092. http://dx.doi.org/10.1371/journal.pone.0103092

34. Antachopoulos C, Tsolia MN, Tzanakaki G, Xirogianni A, Dedousi O, Markou G, et al. Parapneumonic pleural effusions caused by Streptococcus pneumoniae serotype 3 in children immunized with 13 -valent conjugated pneumococcal vaccine.
Pediatr Infect Dis J. 2014;33:81-3. http://dx.doi.org/10.1097/ INF.0000000000000041

35. Syrogiannopoulos GA, Michoula AN, Tsimitselis G,

Vassiou K, Chryssanthopoulou DC, Grivea IN. Pneumonia with empyema among children in the first five years of high coverage with 13-valent pneumococcal conjugate vaccine. Infect Dis (Lond). 2016;48:749-53. http://dx.doi.org/10.1080/23744235.2016.1192720

36. Moraga-Llop F, Garcia-Garcia J-J, Díaz-Conradi A, Ciruela P, Martínez-Osorio J, González-Peris S, et al. Vaccine failures in patients properly vaccinated with 13 -valent pneumococcal conjugate vaccine in Catalonia, a region with low vaccination coverage. Pediatr Infect Dis J. 2016;35:460-3. http://dx.doi.org/ 10.1097/INF.0000000000001041

Address for correspondence: M. Ramirez, Universidade de Lisboa, Faculdade de Medicina, Instituto de Microbiologia, Instituto de Medicina Molecular, Av Prof. Egas Moniz Lisboa 1649-028, Portugal; email: ramirez@fm.ul.pt

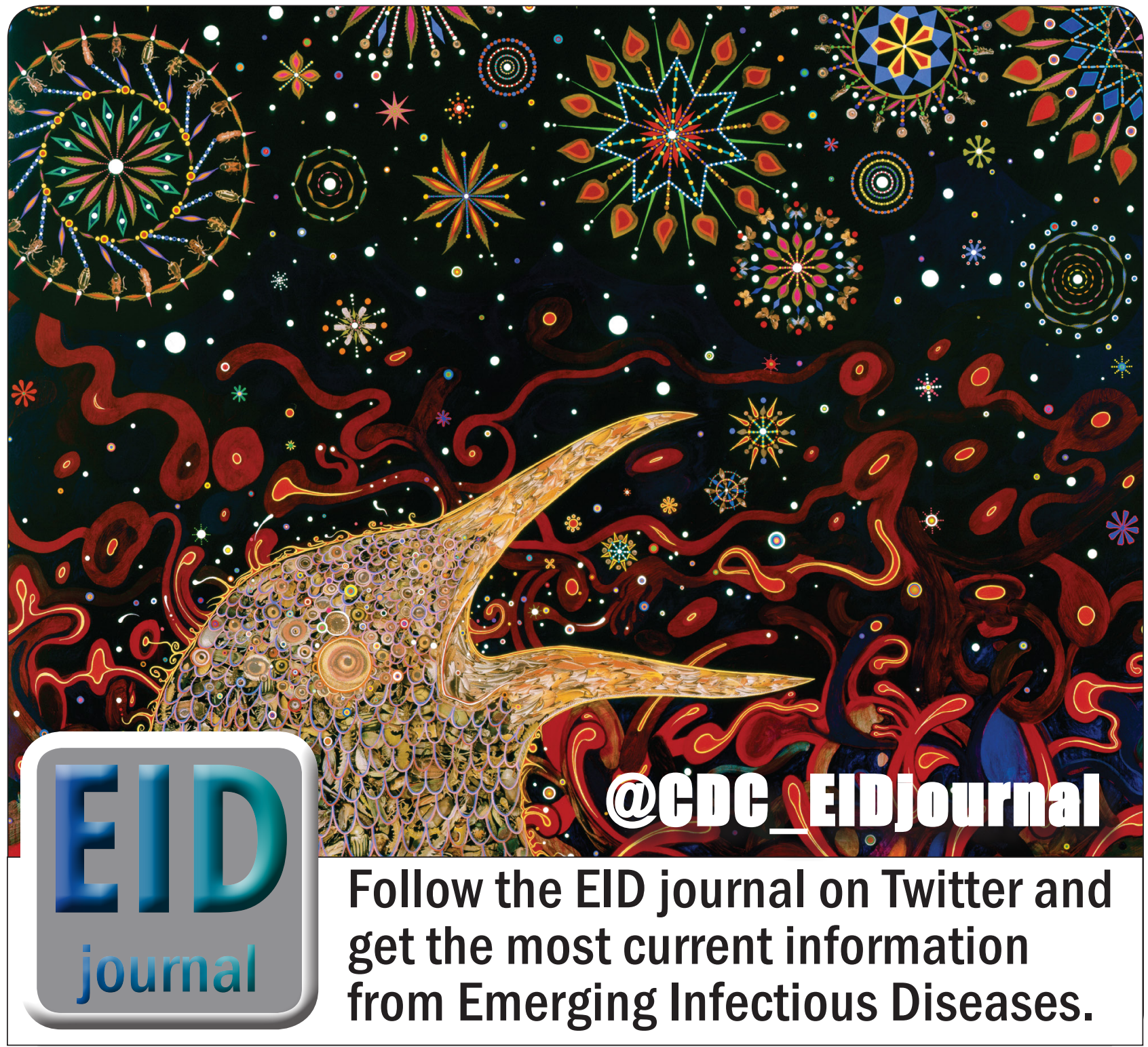

